\title{
Hidrogeologia e geometria dos aquíferos das formações cretáceas Içá e Solimões, Bacia Paleozoica do Solimões, na região de Urucu, Amazonas
}

\author{
Paulo Henrique Ferreira Galvão ${ }^{1 *}$, José Geilson Alves Demétrio ${ }^{2}$, Eliene Lopes de Souza ${ }^{3}$, \\ Cleane do Socorro da Silva Pinheiro ${ }^{3}$, Marcus Paulus Martins Baessa ${ }^{4}$
}

\begin{abstract}
Resumo As águas subterrâneas desempenham um papel fundamental no ciclo da água na região Amazônica e constituem uma reserva expressiva de boa qualidade, podendo ser utilizadas para diversos fins. As informações hidrogeológicas em tal região são ainda muito escassas, restringindo-se apenas aos aquíferos dos depósitos do Cenozoico (formações Solimões e Alter do Chão), com estudos concentrados particularmente nas regiões de Manaus, no Amazonas, e de Belém, no Pará. Dessa forma, são necessários estudos hidrogeológicos sistemáticos que permitam caracterizar os aquíferos quanto à geometria, à produtividade, às condições de recarga, entre outros, possibilitando aperfeiçoar a explotação e o uso da água subterrânea, de modo a garantir sua sustentabilidade. O presente trabalho, desenvolvido na Província Petrolífera de Urucu, município de Coari, estado do Amazonas, teve como objetivo a caracterização hidrogeológica do Sistema Aquífero Içá-Solimões. O estudo revelou que este sistema possui espessura média de $50 \mathrm{~m}$, com superfície convexa, revelada por meio do mapa de isóbatas. O fluxo da água subterrânea é em direção ao Rio Urucu (SSE/NNW), concordante com a superfície topográfica. Os valores médios de transmissividade, coeficiente de armazenamento e condutividade hidráulica foram de $3 \times 10^{-3} \mathrm{~m}^{2} / \mathrm{s}, 5 \times 10^{-4}$ e $1 \times 10^{-4} \mathrm{~m} / \mathrm{s}$, respectivamente. Concluiu-se que se trata de um aquífero do tipo livre-confinado, apresentando um bom potencial de explotação, sendo utilizado para abastecimento da província.
\end{abstract}

Palavras-chave: caracterização hidrogeológica; Sistema Aquífero Içá-Solimões; água subterrânea.

\begin{abstract}
Hydrogeological and geometric characterization of the Iça and Solimões Formations in Urucu area, Amazonas state. Groundwater has a fundamental role in the water cycle in the Amazon region and constitutes a significant good-quality reserve of water, which can be used for various purposes. The hydrogeological information of this region are still very scarce, being restricted only to the aquifers of the Cenozoic deposits (Solimões and Alter do Chão Formations), with studies particularly concentrated in the region of Manaus, Amazonas State, and Belém, in Pará State. Thus, systematic studies are needed for analysis of the hydrogeological conditions, in order to optimize the exploitation and use of groundwater to ensure sustainability, as well as to characterize the aquifer geometry, productivity, recharge conditions, among others. This research was performed in Urucu Oil Province, Coari county, State of Amazonas, Brazil. The main objective was the hydrogeological characterization of the Içá-Solimões Aquifer System. The study showed that this system has a 50-meter average thickness, with a convex shaped geometry as revealed by isobaths mapping. The potentiometry showed that the behavior of the groundwater flow is consistent with the topographic surface, coming toward the river Urucu. The following average values of hydrogeological parameters were observed: transmissivity $=3 \times 10^{-3} \mathrm{~m}^{2} / \mathrm{s}$, storage coefficient $=5 \times 10^{-4}$, and hydraulic conductivity $=1 \times 10^{-4} \mathrm{~m} / \mathrm{s}$. It was concluded that this is an aquifer of the unconfined-confined type, which presents a good potential for exploitation, being already used by the province.
\end{abstract}

Keywords: hydrogeologic characterization; Içá-Solimões Aquifer System; groundwater.

INTRODUÇÃO O trabalho foi desenvolvido na Base Operacional Geólogo Pedro de Moura (BOGPM), na Província Petrolífera de Urucu, município de Coari, situado a $650 \mathrm{~km}$ a Sudoeste de Manaus (Fig. 1), capital de Amazonas, no Brasil. A área de estudo está inserida na bacia sedimentar paleozoica do Solimões, que ocupa uma área de
$948.600 \mathrm{~km}^{2}$ (Barata \& Caputo 2006). As unidades estratigráficas enfocadas foram as formações cretáceas Içá e Solimões.

Este trabalho fez parte do projeto "Caracterização Hidrogeológica para o Uso Sustentável da Água Subterrânea na BOGPM”, fruto de uma parceria entre a Petrobras, a Universidade

\footnotetext{
${ }^{1}$ Universidade de São Paulo - USP, São Paulo (SP), Brasil. E-mail: hidropaulo@gmail.com

${ }^{2}$ Universidade Federal de Pernambuco - UFPE, Recife (PE), Brasil. E-mail: geilson@ufpe.br

${ }^{3}$ Universidade Federal do Pará - UFPA, Belém (PA), Brasil. E-mails: eliene@ufpa.br, cleanessp@gmail.com

${ }^{4}$ Centro de Pesquisas e Desenvolvimento/Petrobrás - CENPES, Rio de Janeiro (RJ), Brasil. E-mail: marcus.baessa@petrobras.com.br

*Autor correspondente
} 
Federal do Pará (UFPA) e a Universidade Federal de Pernambuco (UFPE). Para os aquíferos estudados, adotou-se a denominação Sistema Aquífero Içá-Solimões, do tipo livre-confinado, utilizada por Souza et al. (2011). Foi tida como base a interpretação de dados geológicos disponibilizados pela Petrobras, associados a levantamentos hidrogeológicos de campo desenvolvidos no âmbito desse mesmo projeto. Segundo os mesmos autores, a opção de acrescentar o termo Içá, ao denominado Sistema Aquífero Solimões (ANA 2007), deveu-se, primeiramente, ao fato de na região de Urucu o topo do primeiro aquífero ocorrer em profundidades variando entre 20 a $30 \mathrm{~m}$, zona onde pode ocorrer tanto a
Formação Içá como a Solimões. Assim, devido à dificuldade de separar litologicamente essas duas formações, tendo em vista as semelhanças observadas entre ambas, os autores assumiram que o intervalo de ocorrência do primeiro aquífero insere-se, pelo menos em parte, no domínio da Formação Içá.

A caracterização dos aquíferos do Sistema IçáSolimões, na BOGPM, representa uma contribuição para o conhecimento hidrogeológico na região Norte do Brasil, particularmente na Região Hidrográfica Amazônica (MMA 2006), onde as pesquisas sobre águas subterrâneas são ainda incipientes e concentradas nos aquíferos da Formação Alter do Chão (Aguiar et al. 2002, Souza \& Verma 2006, Tancredi 1996).

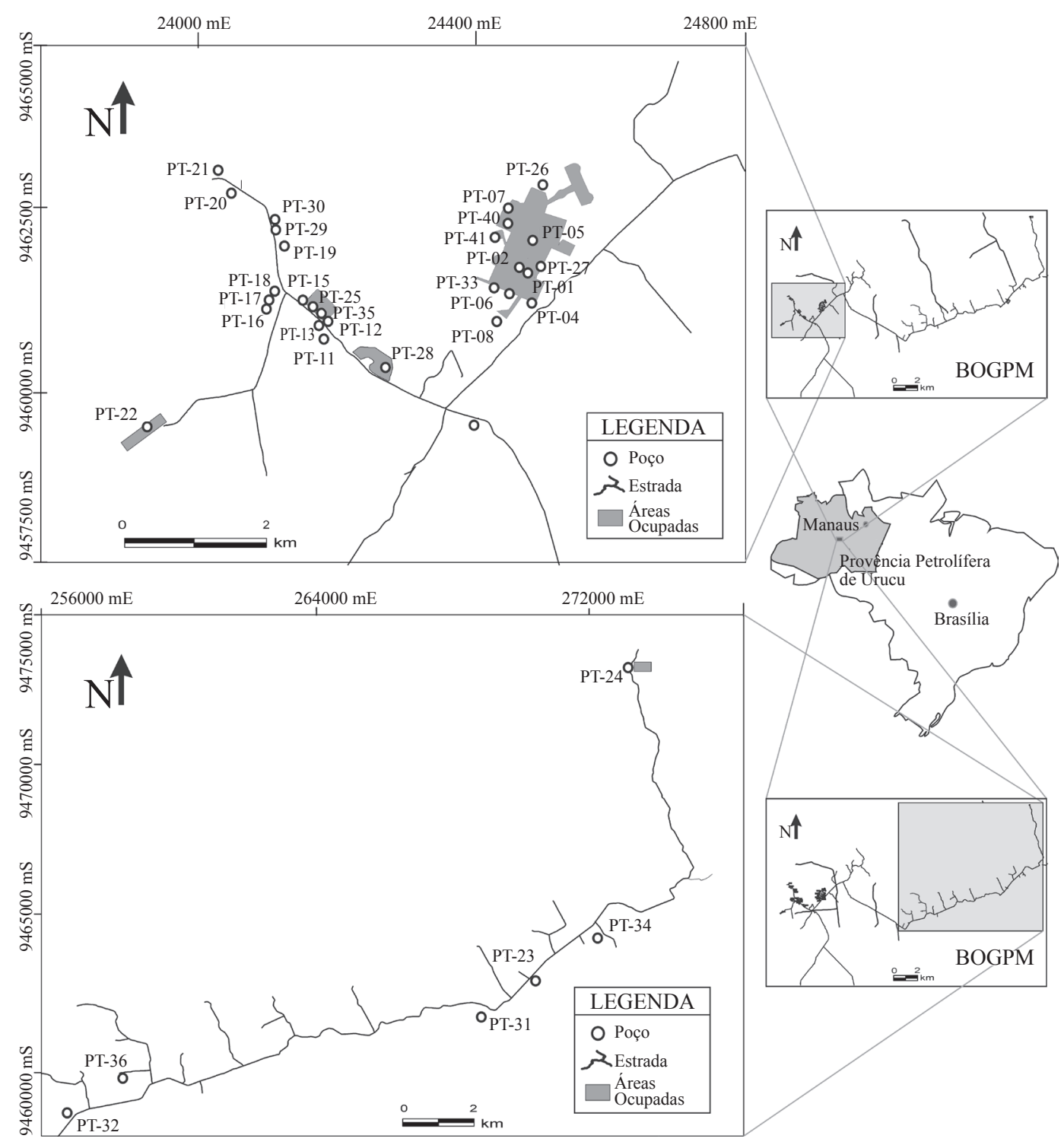

Figura 1 - Localização da província petrolifera de Urucu. As áreas ocupadas são constituídas por alojamentos, depósito e polo industrial Arara. 
ESTUDOS ANTERIORES No estado do Amazonas, estudos sobre águas subterrâneas são muito escassos. De acordo com Aguiar et al. (2002), em Manaus, o aquífero livre Alter do Chão tem espessura aproximada de $200 \mathrm{~m}$, dos quais $175 \mathrm{~m}$ estão saturados. Para porosidade efetiva de $15 \%$ e área de ocorrência de $400 \mathrm{~km}^{2}$, a reserva permanente para esse aquífero foi estimada em $10 \mathrm{~km}^{3}$. Ainda em Manaus, Souza \& Verma (2006) mapearam os aquíferos da Formação Alter do Chão integrando dados da perfilagem geofísica de poços, sondagem elétrica vertical e informações litológicas de amostragem de calha. O estudo mostrou fácies sedimentares arenosa, argilosa, arenoargilosa e o 'Arenito Manaus' depositados em ambiente fluvial e fluviodeltaico. Foram identificadas duas zonas aquíferas: a primeira situa-se nos $50 \mathrm{~m}$ iniciais do perfil e a segunda entre 50 e $290 \mathrm{~m}$ de profundidade; nesta, os corpos arenosos são mais espessos e possuem maior continuidade lateral, apresentando elevado potencial aquífero, sendo captada por poços cuja vazão pode ser próxima dos $300 \mathrm{~m}^{3} / \mathrm{h}$. A pesquisa estimou que $32.500 \mathrm{~km}^{3}$ de água poderiam ser explotados por meio desses poços.

No município de Santarém, no estado do Pará, destaca-se o estudo realizado por Tancredi (1996), que avaliou, entre outros aspectos, as reservas de água subterrânea no sistema hidrogeológico da Formação Alter do Chão. Nesse sistema ocorrem aquíferos confinados de espessuras que perfazem $430 \mathrm{~m}$, intercalados a aquicludes e/ou aquitardes. Essa pesquisa mostrou que as reservas de água subterrânea são expressivas, com volumes de $226 \times 10^{6} \mathrm{~m}^{3}$ para a reguladora e de $86.550 \times 10^{6} \mathrm{~m}^{3}$ para a permanente. Estudos comparativos mostraram que os custos de exploração unitária da água subterrânea de Santarém estão compreendidos entre 38,4 a 42,5\% daquele de explotação unitário da água superficial de Manaus, e entre 64,5 a $71,3 \%$ do custo unitário de explotação da água superficial de Oriximiná, no estado do Pará. No que se refere ao coeficiente de armazenamento ( $\mathrm{S}$ ), o valor máximo obtido por Tancredi (1996) foi de $4,1 \times 10^{-4}$ e o mínimo de $3,3 \times 10^{-4}$; para a condutividade hidráulica $(\mathrm{K})$, o máximo e o mínimo foram de 18,8 e 4,6 m/dia, respectivamente.

OBJETIVOS O trabalho teve como objetivo principal a caracterização dos aquíferos das formações Içá e Solimões, na Província Petrolífera de Urucu. Por sua vez, os objetivos específicos visaram determinar as condições de pressão, a espessura, a extensão, os parâmetros hidrodinâmicos e a potenciometria de tais aquíferos na BOGPM, contribuindo para o uso ecoeficiente e integrado das águas subterrâneas nessa área.

MATERIAIS E MÉTODOS Inicialmente, junto à Petrobras, fez-se um levantamento dos dados existentes, como base cartográfica, mapas de localização, sondagens à percussão, perfis construtivos, litológicos e geofísicos (resistência elétrica, potencial espontâneo e raios gama) dos poços de captação de água, localizados na BOGPM. Esta empresa também disponibilizou perfis dos poços de captação de óleo, dos quais foram obtidas informações sobre litologia e geofísica (resistência elétrica, potencial espontâneo e raios gama) até a profundidade de $465 \mathrm{~m}$.

Além dos levantamentos das informações preexistentes, foram executados, no âmbito do projeto, três sondagens estratigráficas, STG-01, STG-02 e STG-03, com 300, 330 e $150 \mathrm{~m}$ de profundidade, respectivamente. Durante a perfuração, foram coletadas e descritas amostras de calha, a cada metro perfurado; ao término de cada sondagem, foram realizadas perfilagens geofísicas - raios gama, resistência elétrica e potencial espontâneo.

A integração dos dados obtidos permitiu confeccionar seções hidrogeológicas esquemáticas da Província de Urucu, assim como mapas de isóbatas e isópacas. Na elaboração dessas seções e mapas, foram utilizados poços com perfis litológicos e geofísicos com mais de $100 \mathrm{~m}$ de extensão, permitindo informações mais abrangentes da melhor sucessão litológica. Portanto, foi possível determinar as profundidades das primeiras ocorrências do aquífero (para o mapa de isóbatas) e as espessuras totais das camadas arenosas (para o mapa de isópacas). Na determinação das cotas topográficas dos locais dos poços, utilizou-se o programa Global Mapper 8 (Global Mapper Software, LLC, USA), que, por meio de uma imagem SRTM (Shuttle Radar Topographic Mission), possibilitou gerar as informações de declividade e as cotas dos terrenos, em metros.

Na elaboração do mapa potenciométrico foram utilizadas medidas de nível estático (NE), por meio de um medidor elétrico de nível d'água, em duas etapas: a primeira foi realizada de seis a sete de julho de 2008, em época de seca, coletando-se dados dos níveis de 18 poços tubulares; a segunda ocorreu em 22 de maio de 2009, em época de chuvas, medidas em 
24 poços. Os dados de nivelamento e Datum SAD 69 de cada poço foram cedidos pela Petrobras. As coordenadas X e Y, elevação do terreno, cota da boca do poço e medidas de NE foram organizadas em uma planilha Microsoft Office Excel 2007 e, posteriormente, transferidas para o programa Surfer 8 (Golden Software, USA), visando à elaboração dos mapas de contorno potenciométrico, cujo refinamento gráfico foi realizado com o programa CorelDraw X3. Foram elaborados mapas que abrangem toda a BOGPM e incluindo apenas as áreas do Polo Arara, dos alojamentos e do aeroporto, nos períodos de julho de 2008 e maio de 2009. Construiu-se, ainda, um mapa de variação da carga hidráulica, nos mesmos meses.

Para determinar os parâmetros hidrodinâmicos (coeficiente de armazenamento - S, condutividade hidráulica $-\mathrm{K}$ e transmissividade $-\mathrm{T}$ ) dos aquíferos identificados na BOGPM, foram realizados dois testes de aquífero, os quais consistiam em bombear um poço com vazão constante $Q$ e acompanhar a evolução dos rebaixamentos produzidos em um (ou mais de um) poço de observação, situado a uma distância $r$ qualquer daquele que estava sendo bombeado.

Os poços bombeados para os dois testes foram o PT-40 e o PT-16 (Fig. 1). O teste no PT-40 teve duração de 24 horas (1.440 minutos), com as distâncias dos poços de observação PTs 01, 02, 33 e 41 de 82,$5 ; 75,7 ; 100,5$ e $40 \mathrm{~m}$, respectivamente. A vazão utilizada para o teste foi de $60 \mathrm{~m}^{3} / \mathrm{h}$. O valor da espessura média do aquífero considerado foi de $50 \mathrm{~m}$. Para o teste de aquífero no poço PT-16, foram observados os níveis nos PT-17 e 18, situados a 32 e $67 \mathrm{~m}$ de distância, respectivamente. Entretanto, tendo em vista que os poços de observação são utilizados para abastecer um alojamento, eles necessitam ser ligados com frequência. Desse modo, tal teste teve duração de apenas quatro horas, e seu resultado foi utilizado, sobretudo, para fins de comparação com aquele obtido no teste do PT-40. A vazão do teste foi de $12 \mathrm{~m}^{3} / \mathrm{h}$ e a espessura média adotada para o aquífero na área foi também de $50 \mathrm{~m}$, obtida pela interpretação da seção geológica.

Para a medição do NE e acompanhamento da evolução dos níveis dinâmicos (ND), foram utilizados medidores elétricos com graduação milimétrica, enquanto que para a medição e o controle de vazão foi utilizado um medidor ultrassônico (Portaflow 300, da Micronics, USA). A partir de ambos os testes foi possível determinar os parâmetros hidrogeológicos do Sistema Aquífero Içá-Solimões na área estudada. Embora este sistema seja do tipo livre-confinado (Souza et al. 2011), nos dois testes realizados, as curvas rebaixamento versus tempo não evidenciaram feições de recarga, compatíveis com as zonas confinadas do Sistema. Logo, os resultados foram interpretados pelos métodos de Theis (1935) e CooperJacob (1946) para aquíferos confinados não drenantes, em regime transiente.

\section{CONTEXTO GEOLÓGICO DA ÁREA}

A BOGPM está inserida na bacia sedimentar do Solimões, cujo limite com a do Amazonas é realizado por meio do Arco de Purus, como observado na Fig. 2 (Eiras et al. 1994).

A Bacia do Solimões foi implantada em rochas cristalinas e sedimentares proterozoicas da Província Amazônia Central, sendo subdividida em sub-bacia de Jandiatuba, a Oeste, e do Juruá, a Leste, separadas pelo Alto de Carauari. A sequência sedimentar compreende Terciário, Cretáceo, Permiano, Carbonífero, Devoniano, Siluriano e Ordoviciano (Vieira et al. 2005). Evidencia múltiplos eventos de regressão e transgressão marinhas, ligados a processos de subsidência e soerguimento, sendo marcada pela zona de megacisalhamento do Solimões, com um sistema de falhas e dobras com direção N70 $80^{\circ} \mathrm{E}$, em uma distância de quase $1.000 \mathrm{~km}$ (Caputo \& Silva 1991). As principais características das formações de depósitos do Cenozoico (formações Solimões e Içá), que são objetos deste estudo, estão descritas a seguir e na Fig. 3. Embora a hidrogeologia da Formação Alter do Chão não seja enfocada neste trabalho, suas características gerais também são descritas, tendo em vista o seu interesse para o conhecimento das águas subterrâneas da região.

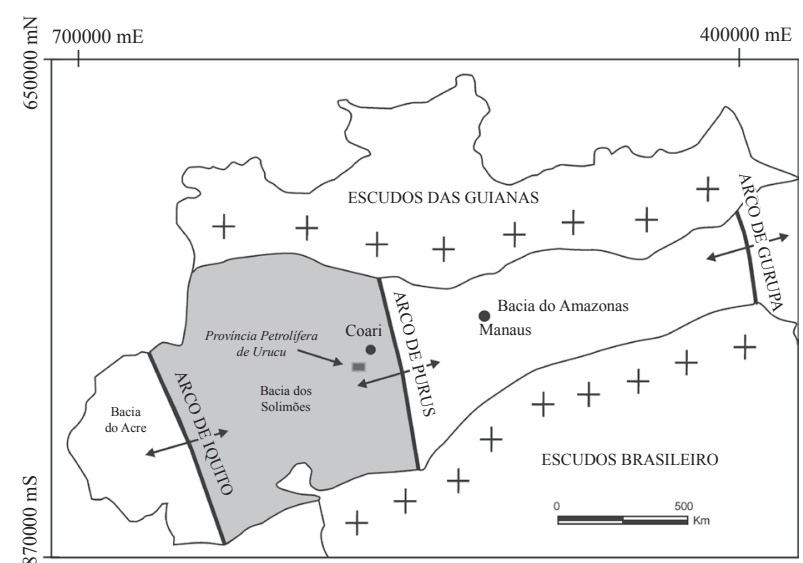

Figura 2 - Localização da Bacia do Solimões (modificado de Oliveira 2010). 


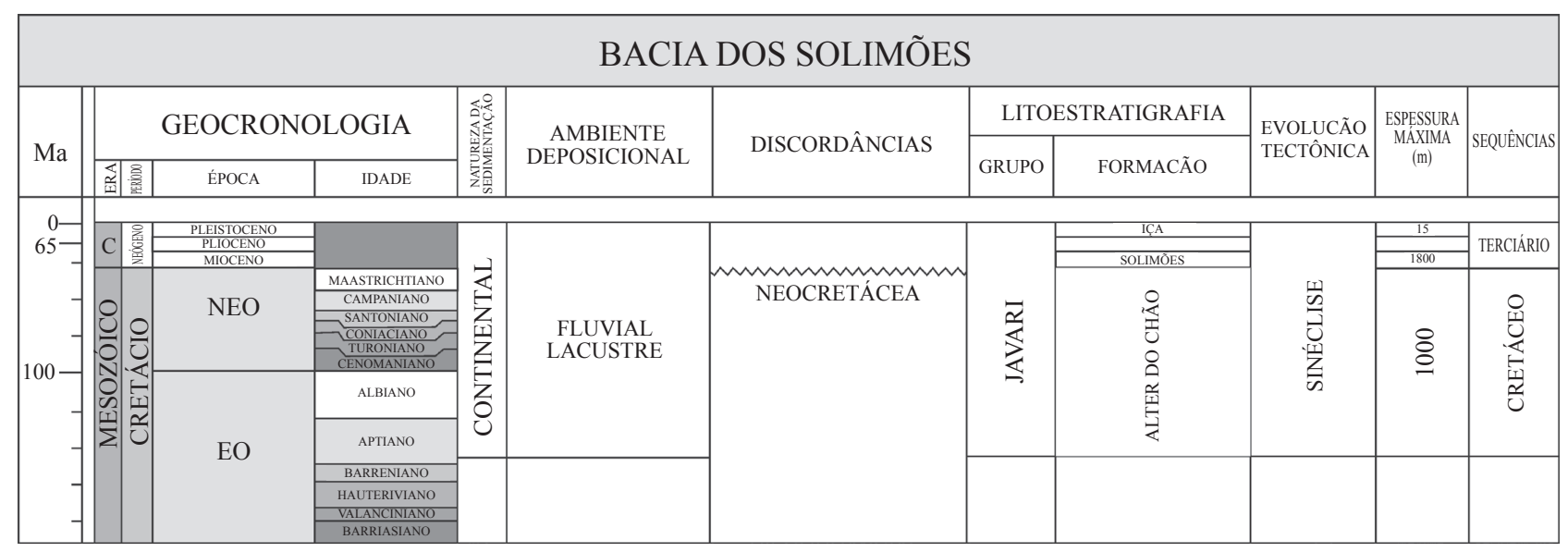

Figura 3 - Carta estratigráfica da Bacia do Solimões (modificado de Eiras et al. 1994).

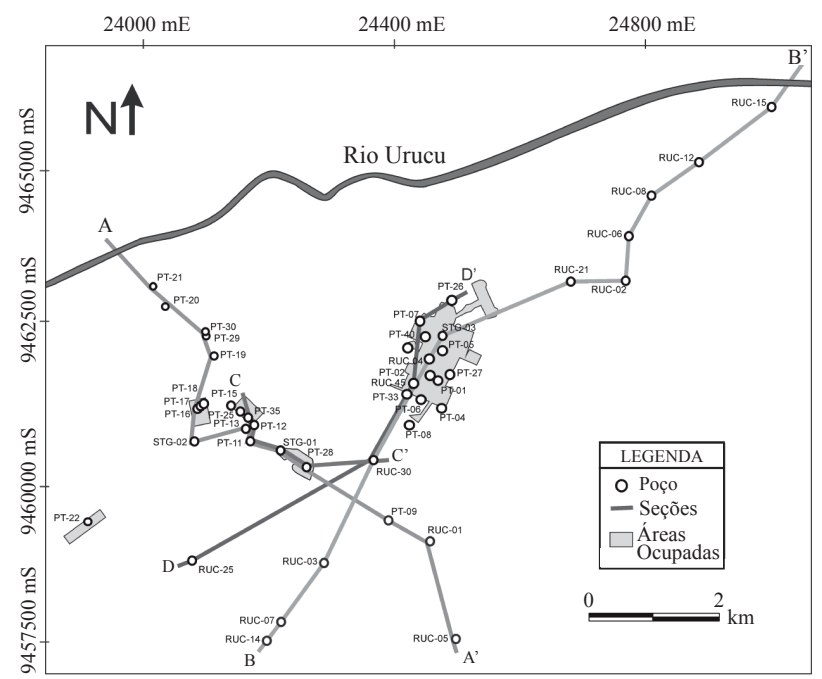

Figura 4 - Disposições das seções hidrogeológica esquemáticas $\left(A-A^{\prime}, B-B^{\prime}, C-C^{\prime} e D-D^{\prime}\right)$.

Formação Içá Consiste de arenitos finos a médios e siltitos, localmente com conglomerados argilosos e colorações amarelo-avermelhadas (Nogueira et al. 2003). Sobrepõe-se discordantemente à Formação Solimões.

Formação Solimões Litologicamente, a Formação Solimões foi definida como uma sucessão de pelitos de cor cinza claro e cinza esverdeado, maciços e laminados, com linhitos intercalados em camadas de 2 a $10 \mathrm{~m}$ de espessura, e arenitos finos a grossos, subangulares a subarredondados (Caputo 1984). As associações esporopolínicas permitem o estabelecimento de três zonas palinológicas, correspondendo ao Mioceno, Mioceno/ Plioceno e Plioceno, sendo sugeridos um ambiente deposicional fluvial meandrante fino e alguns lagos formados por canais abandonados (Cruz 1987).

Formação Alter do Chão Termo aplicado aos arenitos grossos, friáveis e de cores variadas, que recobrem os estratos paleozoicos da Bacia do Amazonas (Caputo et al. 1971, 1972). Na Bacia do Solimões, a Formação Alter do Chão interpõe-se em discordância angular entre o Grupo Tefé e a Formação Solimões. $\mathrm{Na}$ ausência de datações nesta bacia, a idade da parte superior da Formação Alter do Chão é estimada como sendo neocretácea, por correlação com a Bacia do Amazonas (Caputo 1984). O ambiente de deposição é continental, com fácies de planície e leques aluviais. Algumas bandas ferrosas podem indicar períodos de formação de lateritas, sob condições sazonais mais úmidas.

\section{RESULTADOS E DISCUSSÃO}

\section{Caracterização da geometria do Sistema Aquífero} Içá-Solimões A partir da correlação e interpretação dos dados obtidos, foram identificados e associados os elementos geológicos e topográficos, e confeccionadas as seções hidrogeológicas esquemáticas A-A', B-B', C-C' e D-D', cujas localizações são mostradas na Fig. 4. De acordo com essas seções (Figs. 5 a 8), o pacote constituído pelas formações Içá e Solimões possui espessura média de $300 \mathrm{~m}$, estando sobreposto à Formação Alter do Chão.

De uma forma geral, há na região, primeiramente, a ocorrência de argilitos arenosos ou arenitos argilosos, com espessura média de $25 \mathrm{~m}$, alcançando localizadamente $50 \mathrm{~m}$. Essa camada argilosa recobre arenitos finos a médios, de coloração cinza esverdeado a castanho avermelhados, apresentando, em alguns locais, intercalações de lentes de argila, com espessuras e extensões variadas. Tais arenitos podem alcançar profundidades de até 100 a $120 \mathrm{~m}$ (espessura média de $50 \mathrm{~m}$ ), mostrando boas porosidade e permeabilidade. É nessa camada que está localizada grande parte das 


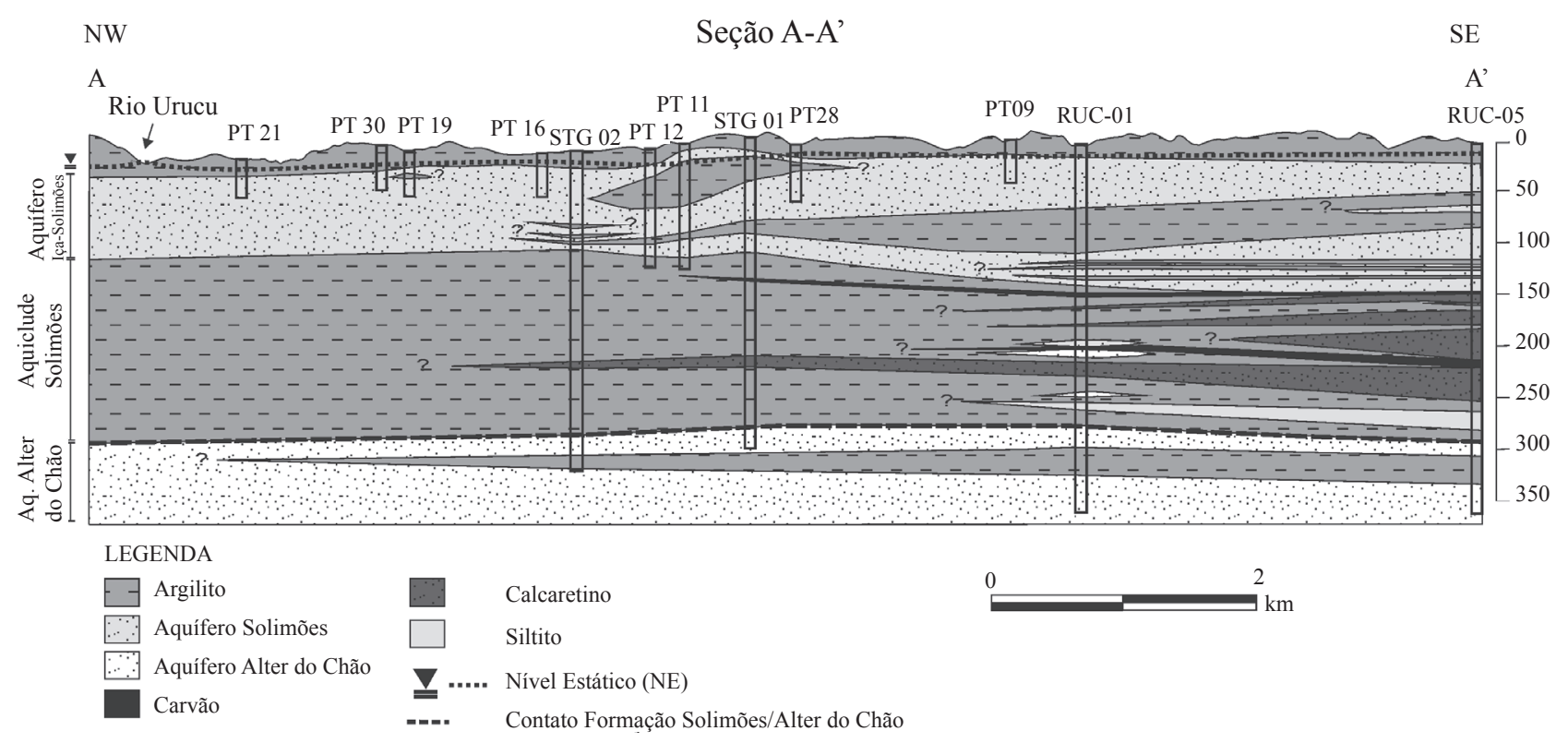

Figura 5 - Seção hidrogeológica esquemática $\left(A-A^{\prime}\right)$ da província petrolifera de Urucu.

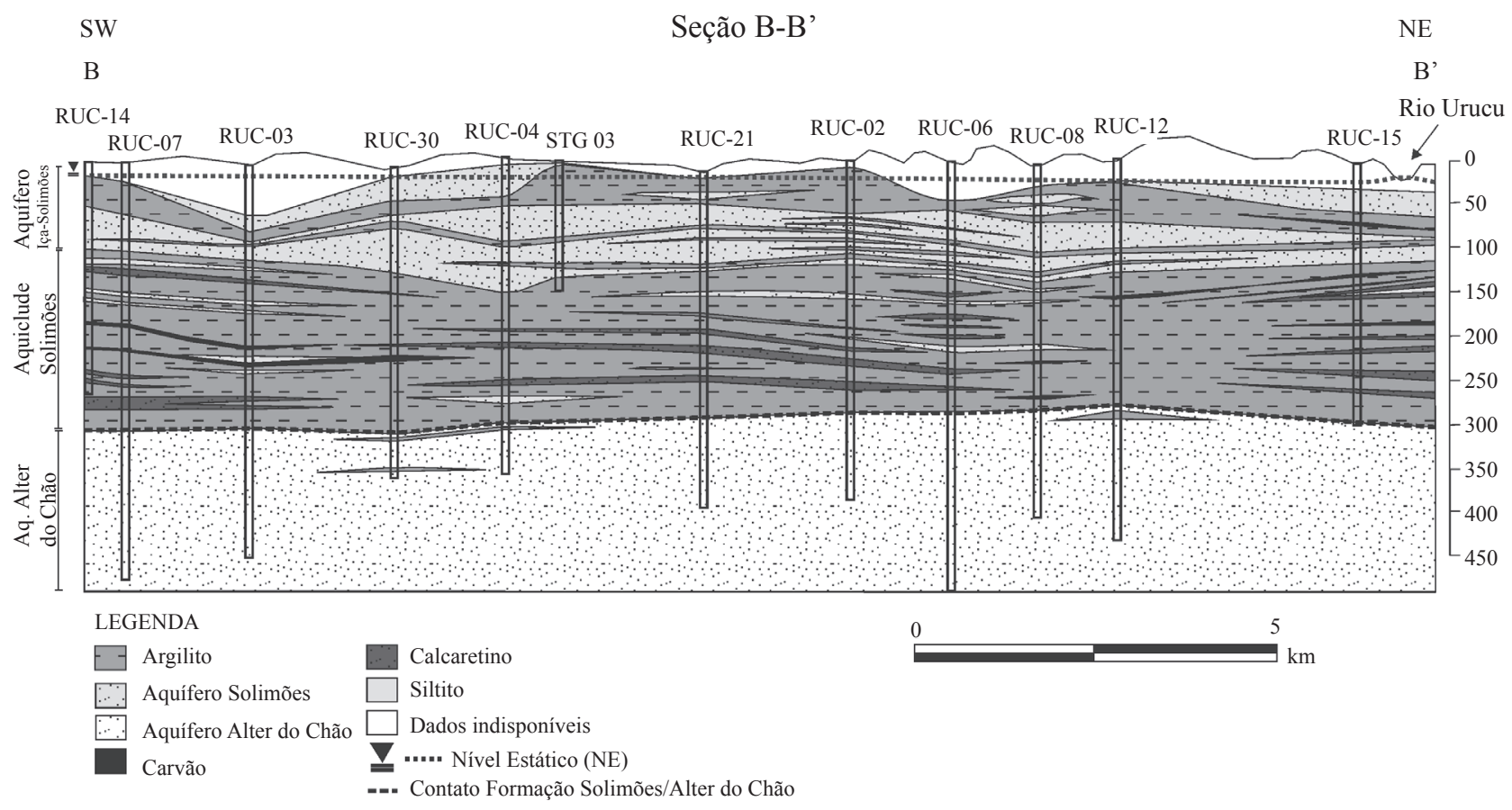

Figura 6 - Seção hidrogeológica esquemática (B-B') da província petrolífera de Urucu.

seções de filtros da maioria dos poços tubulares utilizados para o abastecimento de água na região.

A existência das lentes de argilas intercalando-se aos arenitos permite individualizar dois aquíferos, que constituem o Sistema IçáSolimões: o mais superficial está compreendido entre as profundidades de 20 e $70 \mathrm{~m}$, embora haja uma considerável variação ao longo das seções, enquanto que o mais profundo se encontra no intervalo variando de 80 a $130 \mathrm{~m}$ de profundidade, sendo também marcantes as variações nas seções estudadas. Logo abaixo, ocorre uma espessa camada de argilito (Aquiclude Solimões), com espessura variando entre 150 a $180 \mathrm{~m}$, de coloração cinza claro a cinza esverdeado, a qual, em certos locais, intercala-se com linhitos, arenitos, calcarenitos, coquinas e calcilutitos. Esses últimos constituem lentes de 2 a $10 \mathrm{~m}$ de espessura. A camada de argila faz contato com a Formação Alter do Chão, representada nas seções por arenitos grossos, brancos e algumas lentes de argila, mostrando boas porosidade e permeabilidade (Aquífero 


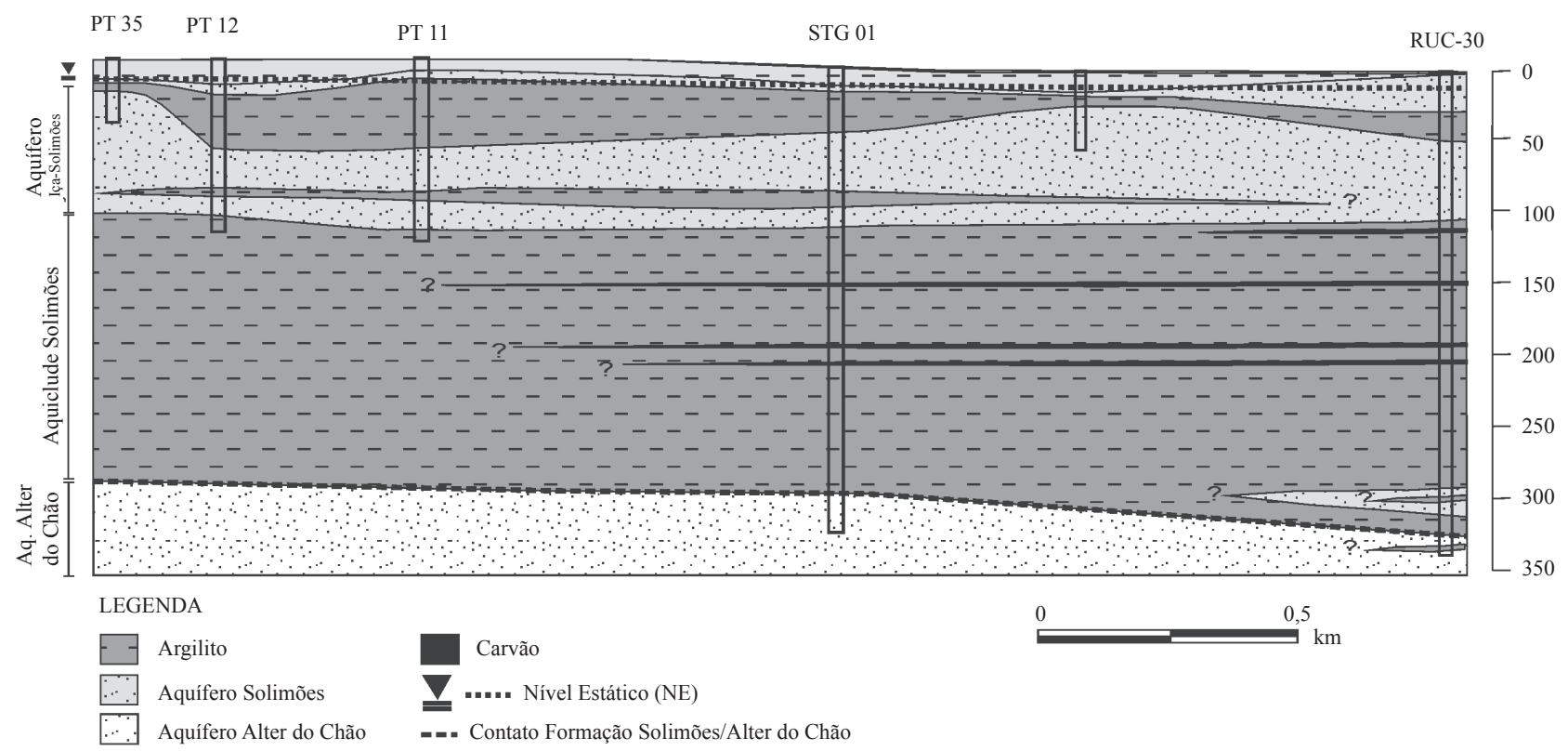

Figura 7 - Seção hidrogeológica esquemática $\left(C-C^{\prime}\right)$ da província petrolífera de Urucu.

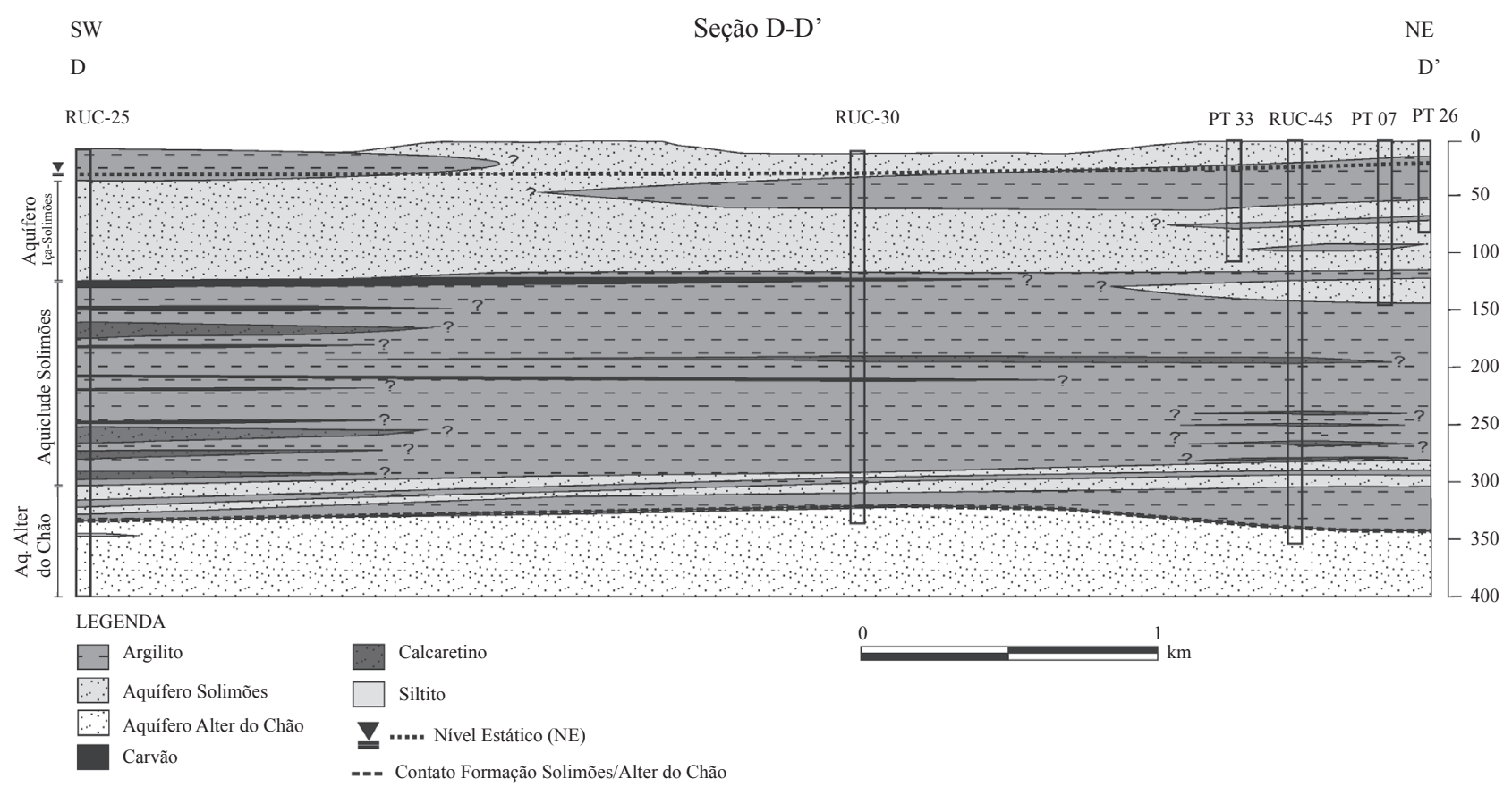

Figura 8 - Seção hidrogeológica esquemática (D-D') da província petrolífera de Urucu.

Alter do Chão) e podendo apresentar grande potencial para explotação. Entretanto, devido à profundidade de ocorrência a partir de $300 \mathrm{~m}$ e à falta de poços captando as águas desse aquífero, são necessárias informações mais detalhadas sobre a química dessas águas para confirmar um possível aumento em sua salinidade, bem como testes de bombeamento para determinar parâmetros hidrodinâmicos mais locais.
Por meio do mapa de isóbatas (Fig. 9), no qual são visualizadas as profundidades das primeiras ocorrências do Sistema Içá-Solimões, a superfície do aquífero superior possui uma forma convexa, com profundidades médias em torno de $50 \mathrm{~m}$. Essa feição é evidenciada por meio de uma parte mais alta, localizada na área central, e de depressões nas partes mais periféricas do mapa. Localizadamente, diferenciam-se três zonas em que as profundidades das 
Tabela 1 - Elevação, nível estático e carga hidráulica (h) dos poços analisados

\begin{tabular}{|c|c|c|c|c|c|c|c|}
\hline \multirow[t]{2}{*}{ POÇO } & \multirow{2}{*}{$\begin{array}{l}\text { Boca do Poço } \\
\text { (m) }\end{array}$} & \multirow{2}{*}{$\begin{array}{l}\text { Elevação } \\
(\mathrm{m})\end{array}$} & \multicolumn{2}{|c|}{$\begin{array}{l}1^{\circ} \text { Campanha } \\
\text { (julho 2008) }\end{array}$} & \multicolumn{2}{|c|}{$\begin{array}{l}2^{\circ} \text { Campanha } \\
\text { (maio 2009) }\end{array}$} & \multirow{2}{*}{$\begin{array}{c}\text { Diferença entre } \\
\text { Cargas Hidráulicas } \\
(\mathrm{m})\end{array}$} \\
\hline & & & $\mathrm{NE}(\mathrm{m})$ & $\mathrm{h}(\mathrm{m})$ & $\mathrm{NE}(\mathrm{m})$ & $\mathrm{h}(\mathrm{m})$ & \\
\hline PT-02 & 1,03 & 68,80 & 24,36 & 45,47 & 25,70 & 44,13 & $-1,34$ \\
\hline PT-04 & 1,15 & 67,91 & - & - & 23,66 & 45,40 & - \\
\hline PT-06 & 0,35 & 68,70 & - & - & 23,86 & 45,19 & - \\
\hline PT-07 & 0,68 & 67,39 & 23,91 & 44,16 & 22,55 & 45,52 & 1,36 \\
\hline PT-09 & 0,60 & 66,95 & - & - & 19,24 & 48,31 & - \\
\hline PT-11 & 0,64 & 66,64 & 19,40 & 47,88 & 18,56 & 48,72 & 0,84 \\
\hline PT-15 & 0,73 & 53,48 & 6,93 & 47,28 & 5,91 & 48,30 & 1,02 \\
\hline PT-16 & 0,30 & 60,12 & 13,39 & 47,03 & 12,30 & 48,12 & 1,09 \\
\hline PT-17 & 0,78 & 60,03 & 13,43 & 47,38 & 12,47 & 48,34 & 0,96 \\
\hline PT-19 & 0,23 & 56,48 & 10,44 & 46,27 & 9,25 & 47,46 & 1,19 \\
\hline PT-20 & 0,45 & 52,46 & 8,14 & 44,77 & 6,72 & 46,19 & 1,42 \\
\hline PT-21 & 1,90 & 53,41 & 10,71 & 44,60 & 11,10 & 44,21 & $-0,39$ \\
\hline PT-24 & 0,57 & 53,59 & 15,16 & 39,00 & 13,50 & 40,66 & 1,66 \\
\hline PT-25 & 0,58 & 66,00 & 19,84 & 46,74 & 18,90 & 47,68 & 0,94 \\
\hline PT-27 & 0,70 & 67,11 & 25,89 & 41,92 & 23,63 & 44,18 & 2,26 \\
\hline PT-33 & 0,75 & 69,17 & 26,50 & 43,42 & 24,95 & 44,97 & 1,55 \\
\hline PT-34 & 0,70 & 61,06 & - & - & 12,49 & 49,27 & - \\
\hline PT-35 & 0,50 & 62,00 & - & - & 13,88 & 48,62 & - \\
\hline PT-41 & 0,55 & 70,06 & 23,60 & 47,01 & 25,54 & 45,07 & $-1,94$ \\
\hline
\end{tabular}

-: dados não coletados.

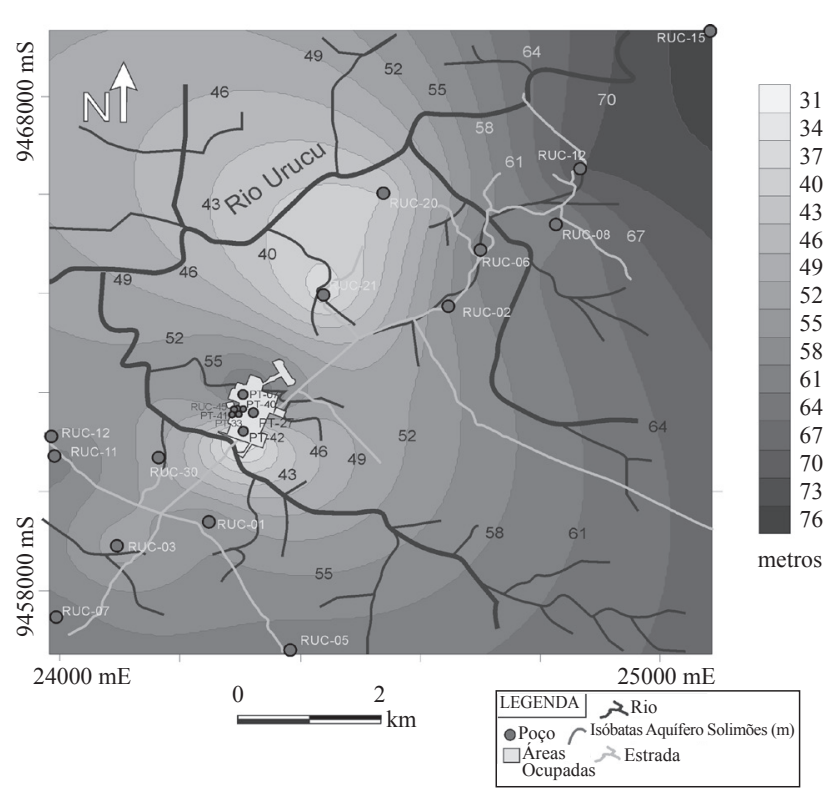

Figura 9-Mapa de isóbatas do Sistema Aquífero IçáSolimões, na Base Operacional Geólogo Pedro de Moura, em que são visualizadas as profundidades das primeiras ocorrências deste sistema. Nota-se que a superficie do aquifero superior possui forma convexa, com profundidades médias em torno de $50 \mathrm{~m}$.

primeiras camadas arenosas são menores: uma próxima ao poço RUC-21 e outras duas nas imediações das áreas ocupadas, estas últimas com os menores valores de isóbatas, próximos a $30 \mathrm{~m}$ de profundidade.

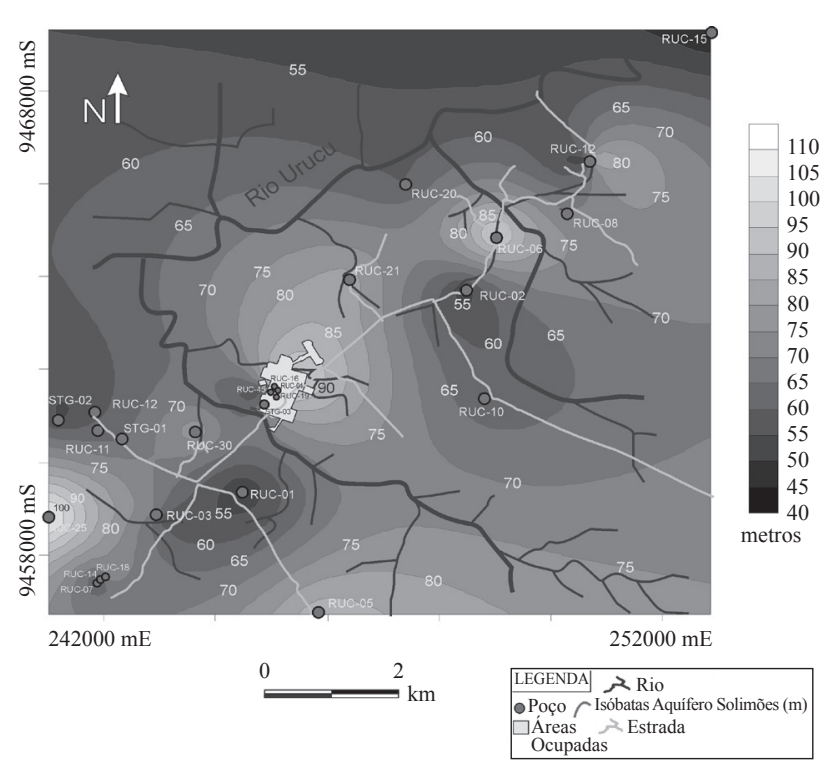

Figura 10 - Isópacas do Aquífero Içá-Solimões, na Base Operacional Geólogo Pedro de Moura, em que são visualizadas as linhas de igual espessura do sistema aquifero, revelando valores variáveis, próximos de 50 até $100 \mathrm{~m}$.

Distanciando-se de tais áreas, o topo do aquífero tende a ter uma maior profundeza de ocorrência, por volta de $75 \mathrm{~m}$, como pode ser visto na parte situada mais Nordeste do mapa, onde se localiza o poço RUC-15. 
O mapa de isópacas (Fig. 10), no qual são visualizadas as linhas de igual espessura do sistema aquífero (espessuras totais considerando a primeira ocorrência do aquífero raso até o contato com o Aquiclude Solimões), revela valores variáveis, próximos de 50 até $100 \mathrm{~m}$. As isópacas de menores valores são vistas nas porções norte-nordeste, próximas ao poço RUC-15, na porção central, no RUC-02, e mais a sudoeste, próximo ao RUC-01. Já os maiores valores das isópacas, na ordem de 90 a 100 m de espessura, são encontrados na parte mais central do mapa e na porção extremo sudoeste, nas imediações do RUC-25, onde foi observada a maior espessura do aquífero. Admitindo-se que essas camadas arenosas possuam permeabilidades razoavelmente constantes, essas regiões, com maiores espessuras, significam maiores transmissividades e, consequentemente, maior capacidade de produção de água.

Potenciometria Na potenciometria geral do Sistema Aquífero Içá-Solimões, na área da BOGPM (Figs. 11 e 12), notou-se que a direção e o sentido geral do fluxo são SSE-NNW, com as linhas equipotenciais registrando convergência de fluxo em direção ao Rio Urucu e a seus tributários, tratando-se de rios efluentes. Com relação aos gradientes hidráulicos, é notado que nas porções central e leste do mapa os valores encontrados estão entre $1 \times 10^{-3} \mathrm{e} 1,4 \times 10^{-3}$, enquanto que, na porção sudoeste, o gradiente hidráulico médio

Tabela 2 - Valores de T, S e K encontrados por meio dos métodos de Theis e Cooper-Jacob

\begin{tabular}{|c|c|c|c|c|}
\hline PT-16 & & $\mathrm{T}\left(\mathrm{m}^{2} / \mathrm{s}\right)$ & $\mathrm{S}$ & $\mathrm{K}(\mathrm{m} / \mathrm{s})$ \\
\hline PT-17 & \multirow{2}{*}{ Theis } & $1,77 \times 10^{-3}$ & $9,32 \times 10^{-4}$ & $3,54 \times 10^{-5}$ \\
\hline PT-18 & & $3,54 \times 10^{-4}$ & $1,36 \times 10^{-4}$ & $7,08 \times 10^{-6}$ \\
\hline PT-17 & \multirow{2}{*}{ Jacob } & $2,21 \times 10^{-3}$ & $6,12 \times 10^{-4}$ & $4,42 \times 10^{-5}$ \\
\hline PT-18 & & $3,42 \times 10^{-3}$ & $8,49 \times 10^{-4}$ & $6,84 \times 10^{-5}$ \\
\hline PT-40 & & $\mathrm{T}\left(\mathrm{m}^{2} / \mathrm{s}\right)$ & $\mathrm{S}$ & $\mathrm{K}(\mathrm{m} / \mathrm{s})$ \\
\hline PT-02 & \multirow{4}{*}{ Theis } & $6,98 \times 10^{-3}$ & $3,21 \times 10^{-4}$ & $1,39 \times 10^{-4}$ \\
\hline PT-41 & & $6,03 \times 10^{-3}$ & $6,42 \times 10^{-4}$ & $1,21 \times 10^{-4}$ \\
\hline PT-33 & & $1,15 \times 10^{-2}$ & $5,76 \times 10^{-3}$ & $2,30 \times 10^{-4}$ \\
\hline PT-01 & & $9,48 \times 10^{-3}$ & $7,69 \times 10^{-4}$ & $1,89 \times 10^{-4}$ \\
\hline PT-02 & \multirow{4}{*}{ Jacob } & $7,52 \times 10^{-3}$ & $2,30 \times 10^{-4}$ & $1,50 \times 10^{-4}$ \\
\hline PT-41 & & $7,96 \times 10^{-3}$ & $3,36 \times 10^{-4}$ & $1,59 \times 10^{-4}$ \\
\hline PT-33 & & $1,02 \times 10^{-2}$ & $5,45 \times 10^{-3}$ & $2,04 \times 10^{-4}$ \\
\hline PT-01 & & $1,01 \times 10^{-2}$ & $8,06 \times 10^{-3}$ & $2,02 \times 10^{-4}$ \\
\hline
\end{tabular}

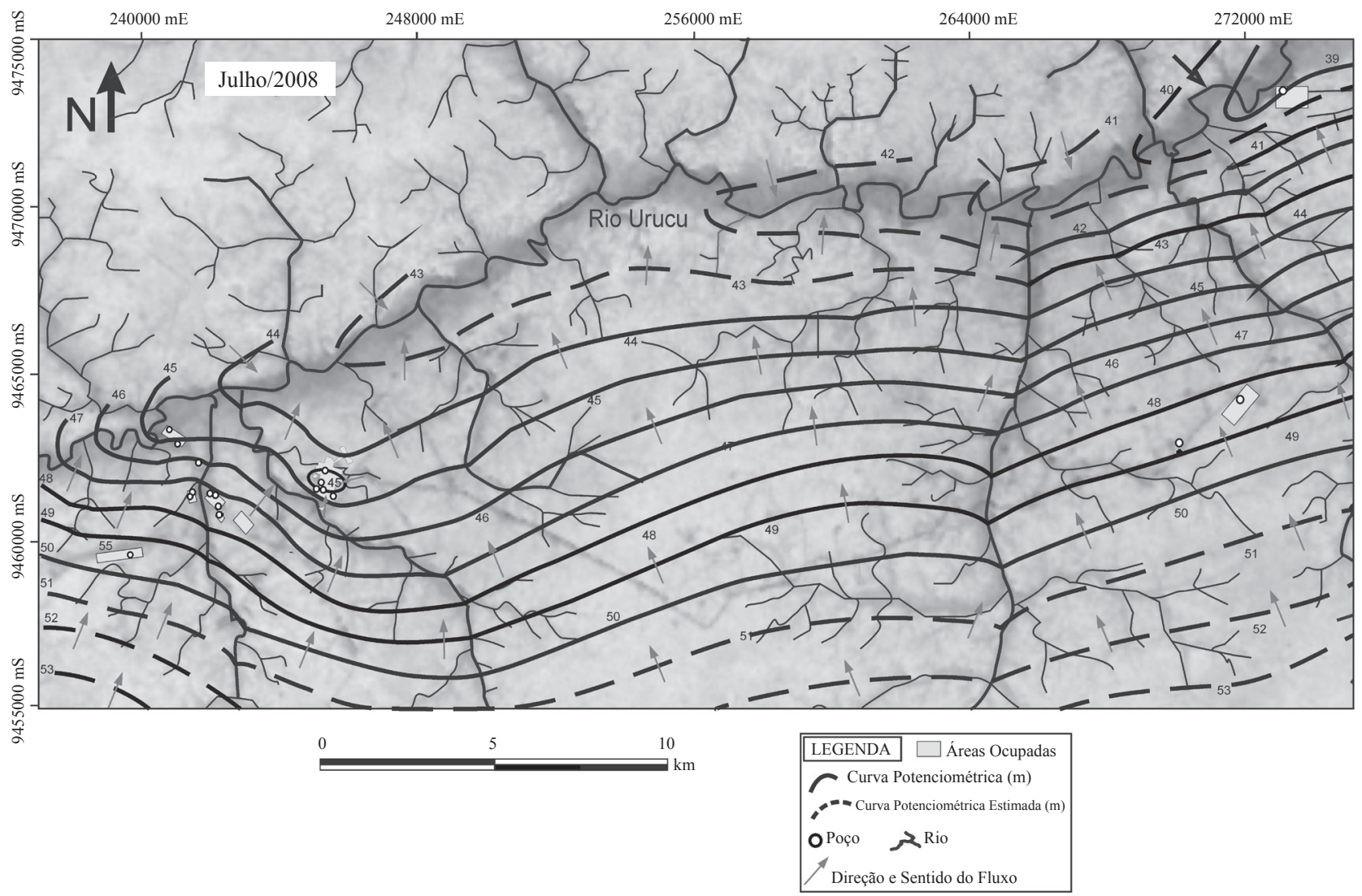

Figura 11 - Potenciometria geral da Base Operacional Geólogo Pedro de Moura, em julho de 2008, com a direção e o sentido geral do fluxo SSE-NNW e as linhas equipotenciais registrando convergência de fluxo em direção ao rio Urucu e seus tributários, tratando-se de rios efluentes. 

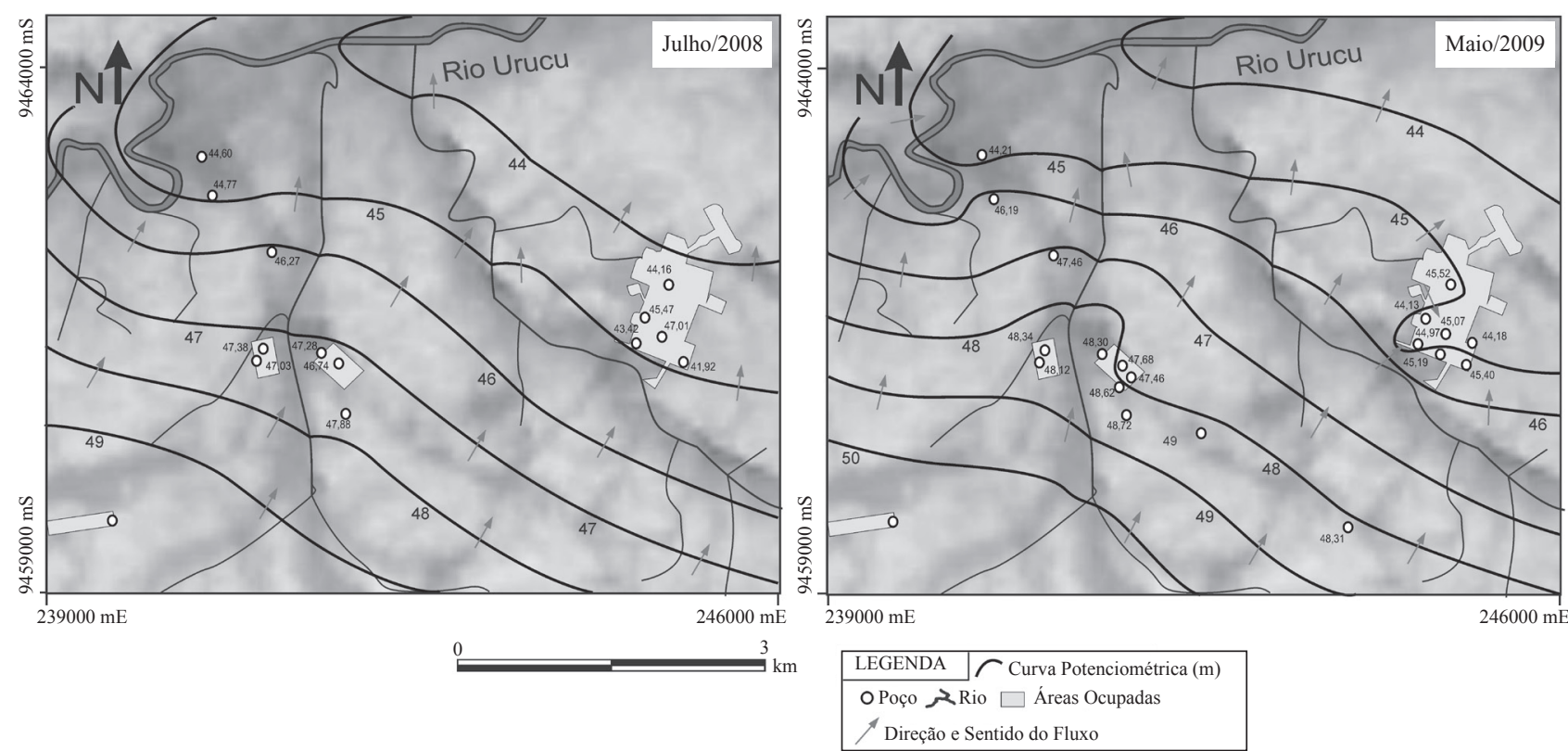

Figura 12 - Potenciometrias detalhadas da Base Operacional Geólogo Pedro de Moura, mostrando convergência de fluxo subterrâneo em direção às áreas ocupadas, seguindo posteriormente em direção ao rio Urucu; esse comportamento pode ser explicado por possiveis influências de bombeamentos nessas áreas.

encontrado foi de $1,3 \times 10^{-3}$. As informações sobre nivelamento e coordenadas Datum SAD 69, de cada poço medido, podem ser observadas na Tab. 1, porém as coordenadas dos poços não constam na mesma por se tratarem de dados internos da Petrobras.

Com relação à potenciometria detalhada, verificam-se, como mostra a Fig. 12, um sentido geral SWNE e uma convergência de fluxo subterrâneo em direção aos canais de drenagem superficial e ao Rio Urucu. Fazendo-se uma comparação entre as cargas hidráulicas obtidas nos poços, em julho de 2008 e em maio de 2009, percebe-se que em dez meses não houve uma grande variação no padrão de fluxo da água subterrânea. Nos dois mapas percebeu-se uma convergência de fluxo subterrâneo em direção às áreas ocupadas, seguindo posteriormente em direção ao Rio Urucu. Tal comportamento pode ser explicado por possíveis influências de bombeamentos nessas áreas.

Na Fig. 13 é mostrada a diferença entre as cargas hidráulicas de julho de 2008 a maio de 2009. No mapa potenciométrico, os valores negativos significam que houve um rebaixamento da superfície potenciométrica de 2008 para 2009 e os positivos, que houve recuperação. As variações ficaram entre 2,26 e -1,94 m, sendo que os valores negativos só foram observados nas áreas ocupadas, locais onde há uma maior quantidade de poços de bombeamento. Vale ressaltar que, nas porções central e leste do mapa, os valores devem ser vistos com reserva, pois nessas áreas o número de poços é reduzido.

\section{Parâmetros hidrodinâmicos do Sistema Aquífero}

Içá-Solimões A interpretação dos testes de aquífero realizados nos poços PT-16 e PT-40 para a obtenção dos parâmetros hidrogeológicos (S, K e T) do Sistema Aquífero Içá-Solimões revelou valores médios de transmissividade ( $\mathrm{T}$ ) e coeficiente de armazenamento (S) de $3 \times 10^{-3} \mathrm{~m}^{2} / \mathrm{s}$ e $5 \times 10^{-4}$, respectivamente. Para uma espessura de $50 \mathrm{~m}$, a condutividade hidráulica $(\mathrm{K})$ média foi de $1 \times 10^{-4} \mathrm{~m} / \mathrm{s}$. Os dados dos testes são mostrados na Tab. 2. Tais parâmetros possuem ordem de grandeza semelhante aos mínimos obtidos para o Aquífero Alter do Chão, em Santarém, observado por Tancredi (1996).

CONCLUSÕES Na área da BOGPM, os arenitos finos a médios, que podem alcançar profundidades de até 100 a $120 \mathrm{~m}$ (com espessuras médias de $50 \mathrm{~m}$ ), com intercalações de lentes de argila de espessuras e extensões variadas, constituem um bom reservatório de água. As intercalações com as lentes de argilas permitem que, em algumas áreas, dois aquíferos sejam individualizados: o mais superficial com topo e base em profundidades próximas de 20 e $70 \mathrm{~m}$, 


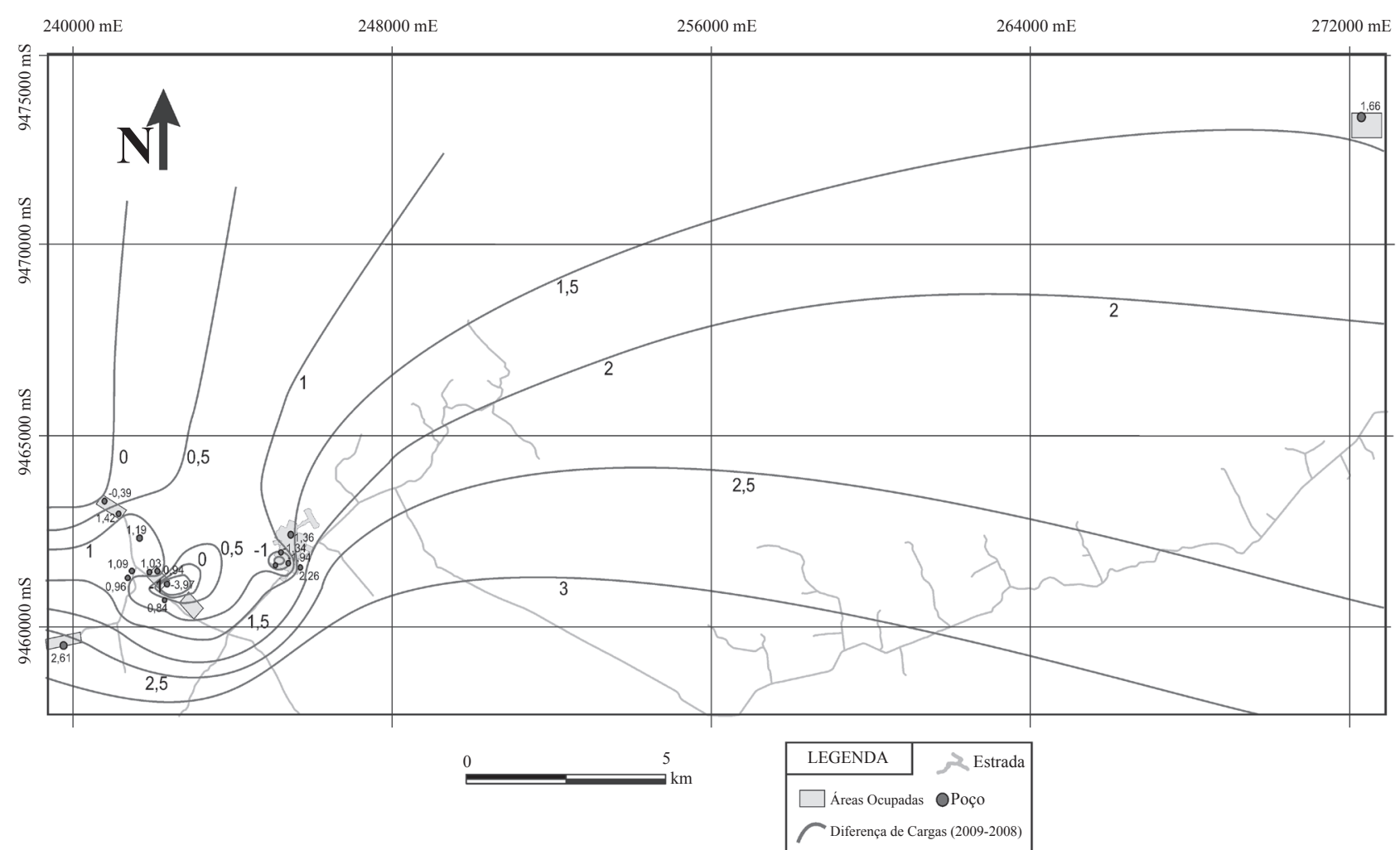

Figura 13 - Mapa da variação de carga hidráulica entre maio de 2009 a julho de 2008. As variações resultaram entre 2,26 e -1,94 m; sendo que os negativos (rebaixamento potenciométrico) foram observados nas proximidades das áreas ocupadas, em que há um maior número de poços de bombeamento.

respectivamente, e o mais profundo com intervalo de profundidades variando de 80 a $130 \mathrm{~m}$. Ambos os aquíferos são hidraulicamente conectados e constituem o Sistema Aquífero Içá-Solimões, do tipo livre-confinado.

O Aquiclude Solimões, logo abaixo deste Sistema, é constituído por argilito com espessura variando de 150 a $180 \mathrm{~m}$, apresentando intercalações de linhitos, arenitos, calcarenitos, coquinas e calcilutitos. Esse aquiclude faz contato com a Formação Alter do Chão, representada por arenitos grossos e algumas lentes de argila (Aquífero Alter do Chão). Os arenitos, mostrando boas porosidade e permeabilidade, podem apresentar grande potencial para a explotação. Entretanto, devido à profundidade e à falta de poços captando localmente as águas do Aquífero Alter do Chão, é importante que sejam obtidas informações mais detalhadas sobre a química dessas águas, para confirmar um possível aumento na sua salinidade. É também relevante que sejam realizados testes de bombeamento, para a obtenção dos parâmetros hidrodinâmicos mais localizados.

Quanto à geometria, o mapa de isóbatas mostra que a superfície do sistema aquífero estudado possui forma convexa, com profundidades médias em torno de $50 \mathrm{~m}$. Essa convecção foi evidenciada por uma parte mais elevada ao centro da área, com valores próximos de $30 \mathrm{~m}$ de profundidade, enquanto que, na parte periférica do mapa, o topo do aquífero ocorre aos 75 $\mathrm{m}$. O mapa de isópacas revelou valores de espessura do sistema aquífero variando próximos de 50 a $100 \mathrm{~m}$.

Os parâmetros hidrodinâmicos médios obtidos por meio dos testes de aquífero foram $\mathrm{T}=3 \times 10^{-3} \mathrm{~m}^{2} / \mathrm{s}$, sendo que $\mathrm{S}=5 \times 10^{-4} \mathrm{e} \mathrm{K}=1 \times 10^{-4} \mathrm{~m} / \mathrm{s}$ são similares em ordem de grandeza aos valores mínimos obtidos para os aquíferos Alter do Chão, em Santarém.

A potenciometria geral do Sistema Aquífero Içá-Solimões, na área da BOGPM, apresentou-se concordante com a superfície topográfica, com direção e sentido gerais do fluxo SSE-NNW, convergindo para o Rio Urucu. Os gradientes hidráulicos, nas porções central e leste da área, situam-se entre $1 \times 10^{-3}$ e $1,4 \mathrm{x}$ $10^{-3}$, enquanto que na porção sudoeste o valor médio encontrado foi de $1,3 \times 10^{-3}$. As feições de cone de rebaixamento observadas são resultados da alteração das condições naturais do fluxo subterrâneo, induzido pelo número de poços de bombeamento na BOGPM.

As diferenças entre as cargas hidráulicas de julho de 2008 a maio de 2009 evidenciaram variações entre 2,26 e -1,94 m, com os valores negativos 
significando rebaixamento da superfície potenciométrica e os positivos, a recuperação. Os resultados negativos foram observados em locais onde há maior quantidade de poços de bombeamento, enquanto que os de recuperação foram vistos nas porções central e leste da área estudada.

O conjunto dos dados geológicos, dos parâmetros hidrodinâmicos e da potenciometria indica que o
Sistema Aquífero Içá-Solimões é do tipo livre-confinado, apresentando um bom potencial de explotação e sendo utilizado para abastecimento da BOGPM.

AGRADECIMENTOS À Petrobras, pelo apoio à presente pesquisa, assim como à equipe do projeto "Caracterização Hidrogeológica para o Uso Sustentável da Água Subterrânea na BOGPM".

\section{Referências}

Aguiar C.J.B., Horbe M.A.R., Filho S.F., Lopes E.S., Moura U.F., Andrade N.M., Diógenes H.S. 2002. Carta hidrogeológica da cidade de Manaus. CPRMAM Manaus, Relatório Interno.

AGÊNCIA NACIONAL DE ÁGUAS (ANA). 2007. Panorama do enquadramento dos corpos d'águal panorama da qualidade das águas subterrâneas no Brasil. Caderno de Recursos Hídricos 5, Brasília, 124 p.

Barata C.F. \& Caputo M.V. 2006. Considerações sobre a visão da CPRM em relação às Bacias paleozóicas do Amazonas e do Solimões, [S.I.].

Caputo M.V. 1984. Stratigraphy, tectonics, paleoclimatology and paleogeography of northern basins of Brasil. PhD Thesis, University of California, Santa Barbara, 586 p.

Caputo M.V., Rodrigues R., Vasconcelos D.N.N. 1972. Nomenclatura estratigráfica da Bacia do Amazonas: Histórico e Atualização. In: Congresso Brasileiro de Geologia, 26, Belém, SBG, Anais, 3:35-46.

Caputo M.V., Rodrigues R., Vasconcelos D.N.N. 1971. Litoestratigrafia da Bacia do Amazonas. Belém: Petrobras, Relatório Interno.

Caputo M.V. \& Silva O.B. 1991. Sedimentação e tectônica da Bacia do Solimões. In: Raja G.P., Gabaglia E.J. Milani. Origem e Evolução das Bacias Sedimentares. Rio de Janeiro: Petrobras, p. 169-193.

Cooper H.H. \& Jacob C.E. 1946. A generalized graphical method for evaluating formational constants and summarizing well field history. Transactions American Geophysical Union, 27:526-634.

Cruz N.M.C. 1987. Quitinozoários da Bacia do Solimões, Brasil. Belém, Convênio CPRM/Petrobras, Relatório Interno.

Eiras J.F., Becker C.R., Souza E.M., Gonzaga F.G., Silva J.G.F., Daniel L.M.F. 1994. Bacia do Solimões. Boletim de Geociências da Petrobrás, 8:17-45.

MINISTÉRIO DO MEIO AMBIENTE (MMA). 2006. Caderno da Região Hidrográfica Amazônica. Ministério do Meio ambiente, Secretaria de Recursos Hídricos, Brasília, 124 p.
Nogueira A.C.R., Arai M., Horbe A.M., Silveira R.R., Silva J.S. 2003. A influência marinha nos depósitos da Formação Solimões na região de Coari (AM): registro da transgressão miocênica na Amazônia ocidental. In: Simpósio de Geologia da Amazônia, 8, Manaus, SBG, Resumos Expandidos.

Oliveira K.S. 2010. Fatores responsáveis pela ocorrência da sílica na água de aquíferos da Formação Solimões, em Urucu-AM com ênfase para a composição mineralógica. Trabalho de Conclusão de Curso, Centro de Geociências, Universidade Federal do Pará, 98 p.

Souza E.L., Galvão P.H.F., Pinheiro C.S.S., Baessa M.P.M., Demétrio J.G.A., Brito W.R.R. 2011. Síntese dos Estudos Hidrogeológicos nas Bacias Sedimentares do Amazonas e do Solimões: Base para Uso e Proteção da Água Subterrânea nos Sistemas Aquíferos Içá-Solimões e Alter do Chão. Revista do Instituto Geológico, Série Científica, São Paulo (no prelo).

Souza L.S.B. \& Verma O.P. 2006. Mapeamento de aquíferos na cidade de Manaus/AM (zonas norte e leste) através de perfilagem geofísica de poço e sondagem elétrica vertical. Revista de Geologia, 19(1):111-127.

Tancredi A.C.F.N.S. 1996. Recursos hídricos subterrâneos de Santarém. Fundamentos para uso e proteção. Tese de Doutorado, Centro de Geociências, Universidade Federal do Pará, 154 p.

Theis C.V. 1935. The relation between the lowering of the piezometric surface and the rate and duration of discharge of a well using ground-water storage. In: Transactions American Geophysical Union, $16^{\text {th }}$ Annual Meeting, part 2.

Vieira A.F.G., Molinari D.C., Albuquerque A.R.C. 2005. Dinâmica erosiva em estradas: BR-174 e Urucu (Amazonas). In: II Simpósio Sobre Solos Tropicais e Processos Erosivos no Centro-Oeste, Universidade Federal de Goiás, p. 49-58.

Manuscrito ID 24771

Recebido em: 23/10/2011 Aprovado em: 11/10/2012 